\title{
Gastrointestinal stromal tumors (GISTs) with remarkable cystic change: a specific subtype of GISTs with relatively indolent behaviors and favorable prognoses
}

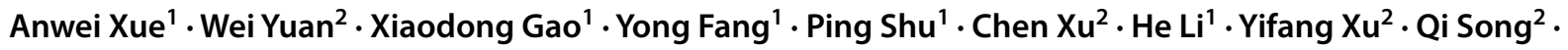 \\ Yingyong $\mathrm{Hou}^{2} \cdot$ Kuntang Shen ${ }^{1}$
}

Received: 11 November 2018 / Accepted: 24 January 2019 / Published online: 28 March 2019

(c) Springer-Verlag GmbH Germany, part of Springer Nature 2019

\begin{abstract}
Purpose Gastrointestinal stromal tumors (GISTs) are typically solid neoplasms with small cystic change detected occasionally but in rare instances may present predominantly as cystic lesions. The histopathologic features and prognoses of cystic GISTs (cGISTs) are poorly understood.

Methods We herein reviewed 20 cGISTs resected or consulted in our institution from January 1, 2003 to December 31, 2014. Results Of the 20 patients included, the mean age was 61 years and the male-to-female ratio was 9:11. The original locations were the stomach $(n=10,50 \%)$, the small intestine $(n=9,45 \%)$ and the omentum $(n=1,5 \%)$. Indistinct diagnosis or misdiagnosis was established in 15 cases based only on preoperative radiology. Grossly, the cystic component made up the bulk of masses and was filled by dark bloody fluid and necrotic debris in 18 cases. Microscopically, cyst wall was composed of neoplastic spindle $(n=14,70 \%) /$ epithelioid cells $(n=6,30 \%)$ and collagenous fiber, with necrotic debris and granulation tissue lining on the inner surface. cGISTs resembled their solid counterparts in terms of morphology and immunohistology but demonstrated fewer malignant parameters. $c$-kit or PDGFR $\alpha$ mutations were detected in eleven cases with the remaining being wild type for these two mutations. Although classified as intermediate or high ( 3 and 17, respectively) risk of recurrence according to modified National Institute of Health criterion, most patients with cGISTs experienced long-term recurrence-free survival without adjuvant imatinib.

Conclusions Cystic GISTs is a relatively indolent subset of GISTs with favorable prognoses and adjuvant imatinib should be a prudent consideration.
\end{abstract}

Keywords Gastrointestinal stromal tumors · Cystic change $\cdot$ Prognosis

\section{Introduction}

Gastrointestinal stromal tumors (GISTs) represent the most common mesenchymal tumors arising from the digestive tract, with an estimated annual incidence of 10-20 per

Anwei Xue and Wei Yuan contributed equally to this work.

Yingyong Hou

houyingyong@hotmail.com

$\triangle$ Kuntang Shen

shen.kuntang@zs-hospital.sh.cn

1 Department of General Surgery, Zhongshan Hospital, Fudan University, NO. 180 Fenglin Road, Shanghai 200032, China

2 Department of Pathology, Zhongshan Hospital, Fudan University, NO. 180 Fenglin Road, Shanghai 200032, China million individuals in western countries (Corless 2014). The majority of GISTs are located in the stomach (60-70\%), small intestine (25-35\%) and duodenum (5\%) (Miettinen and Lasota 2006). Immunohistochemical and ultramicrostructural findings indicate that GISTs may originate from the intestinal cells of Cajal, which serve as pacemakers for peristaltic contractions (Kindblom et al. 1998). About 85-95\% of GISTs harbor activating mutations in c-kit or PDGFR $\alpha$ that drives the pathogenesis and progression of the disease (Fletcher et al. 2002; Heinrich et al. 2003). Imatinib mesylate, which targets KIT and PDGFR $\alpha$, has emerged as an effective therapeutic alternative for advanced GISTs while surgical resection remains the mainstay treatment for resectable ones (von Mehren et al. 2018).

GISTs are typically solid, sometimes with small cystic area developed, but rarely manifest as predominant cystic 
neoplasms. To date, reports of this uncommon form of GISTs have comprised mostly case reports focusing mainly on its clinical and radiographic features (Hamza et al. 2016; Okano et al. 2015; Shaikh et al. 2015; Sun et al. 2016; Takahashi et al. 2010; Wang et al. 2017; Zhu et al. 2014). There is very limited information in the literature relating to the pathologic features and prognoses of GISTs undergoing extensive cystic change. To better elucidate the characteristics of such lesions, we herein undertook this study of the clinical and morphologic features, the prognoses, and the mutational status of 20 affected patients.

\section{Materials and methods}

Study approval was obtained from the institutional review board at Zhongshan Hospital, Fudan University. Surgical pathology database and consultation files of our hospital were queried for GISTs with cystic change from January 1, 2003 to December 31, 2014. The diagnosis of "cystic gastrointestinal stromal tumors (cGISTs)" was established if the proportion of cystic component was larger than $75 \%$ and cyst wall was relatively regular by corresponding gross reports and/or preoperative radiology reports. A total of 20 cases were retrieved, 10 from the surgical pathology database and 10 from the consultation files. Patient variables included age, sex, symptoms on presentation, preoperative radiology and medical history.

Gross pathology reports were assessed for location, size, whether unilocular or multilocular, cystic fluid and septa thickness of the tumor. Hematoxylin and eosin-stained slides or corresponding scanned photographs were reviewed by two experienced pathologists for cellular type (spindle, epithelioid or mixed), cellularity, nuclear atypia, mitotic activity (number of mitoses per 50 high power fields). Lymph node metastasis, vascular, fat, nerve or mucosal infiltration, mitoses $\geq 10 / 50 \mathrm{HPF}$, muscularis propria infiltration, coagulative necrosis, perivascular pattern and severe nuclear atypia were considered as malignant biological behaviors and evaluated in all cases (Hou et al. 2009a, b).

Immunohistochemistry of CD117, desmin and CD34 were performed in all cases using formalin-fixed paraffinembedded tissue sectioned at $4 \mu \mathrm{m}$ while S-100, SMA and DOG-1 immunostain were available for analysis in a varying number of cases. Selected mutation hotspots in $c$-kit exons 9, 11, 13 and 17 as well as PDGFR $\alpha$ exons 12, 14 and 18 were examined using polymerase chain reaction (PCR) and Sanger sequencing.

To compare the prognostic factors and outcomes between solid and cystic GISTs, our surgical pathology database was searched for solid GISTs of comparable external size and resected during the same period. Finally, 200 counterparts were identified and clinicopathological characteristics were compared using Chi square test or non-parametric test. Recurrence-free survival (RFS) was defined as the period between surgical resection and radiologic evidence of recurrence. Survival curves were computed by Kaplan-Meier product limit method with intergroup difference compared by log-rank test. All the tests were two-sided and statistical significance was defined as a $P$ value $<0.05$.

\section{Results}

\section{Clinical features}

Clinical and follow-up data are summarized in Table 1. Of the 20 patients included in this study, 9 were males and 11 females, with a mean age of 61 years (range $31-73$ years) at diagnosis. Clinical presentations were known in 16 patients: 5 patients presented with abdominal pain or discomfort, 4 had gastrointestinal bleeding and 2 presented with abdominal mass. The remaining 5 patients were discovered incidentally by physical or imaging examinations for other reasons. The original location of cGISTs were the stomach in ten patients, the jejunum or ileum in seven, the duodenum in two and the omentum in one. Preoperative computed tomography $(\mathrm{CT})$ or magnetic resonance imaging (MRI) reports were available for all patients but did not provide robust evidence for differential diagnosis with other cystic lesions. cGISTs usually demonstrated as an exophytic, well-defined, low-density mass with peripheral enhancement on contrast imaging (Fig. 1a, b). Endoscopic ultrasound (EUS) was performed only in 1 patient and showed a hypoechoic structure arising from the fourth layer of the stomach.

\section{Pathologic findings}

Pathologic findings are presented in Table 2. On macroscopic examination, cGISTs appeared as soft, well-circumscribed masses and ranged in size from 7 to $20 \mathrm{~cm}$ with a mean of $11.5 \mathrm{~cm}$ (Fig. 1c, d). Most of the neoplasms were unilocular $(n=15,75 \%)$. On sectioning, the cut surface varied in color from gray/white to red/brown depending on the degree of hemorrhage. The cystic component made up the vast majority of the masses and was surrounded by neoplastic parenchyma variable in thickness (range 0.1-4.5 cm). Most of the cysts $(14 / 16,87.5 \%)$ were filled by dark bloody fluid and necrotic debris but one contained grey-green turbid, the other light-yellow fluid.

Microscopically, cyst wall was composed of neoplastic spindle $(n=14,70 \%) /$ epithelioid cells $(n=6,30 \%)$ and collagenous fiber with necrotic debris and granulation tissue lining on the inner surface (Fig. 2a). The degree of cellularity varied in different cases and areas but was moderate in general. In rare cases were the cyst wall occupied by 
Table 1 Clinical and follow-up information of 20 cases of cGIST

\begin{tabular}{|c|c|c|c|c|c|c|c|}
\hline Case & Age (years)/sex & Clinical presentation & Radiologic findings & Location & Treatment & $\begin{array}{l}\text { Follow- } \\
\text { up } \\
\text { (months) }\end{array}$ & Status \\
\hline 1 & $66 \mathrm{M}$ & NA & $\begin{array}{l}\text { Abdominal occupying } \\
\text { lesion }\end{array}$ & Small intestine & Laparotomy & 60 & ANED \\
\hline 2 & $71 \mathrm{~F}$ & Gastrointestinal bleeding & $\begin{array}{l}\text { Abdominal occupying } \\
\text { lesion }\end{array}$ & Stomach & Laparotomy & 143 & ANED \\
\hline 3 & $55 \mathrm{~F}$ & Abdominal discomfort & $\begin{array}{l}\text { Occupying lesion between } \\
\text { liver and stomach }\end{array}$ & Stomach & Laparotomy & 103 & ANED \\
\hline 4 & $42 \mathrm{M}$ & NA & $\begin{array}{l}\text { Abdominal occupying } \\
\text { lesion }\end{array}$ & Small intestine & Laparotomy & 128 & ANED \\
\hline 5 & $50 \mathrm{~F}$ & Gastrointestinal bleeding & $\begin{array}{l}\text { Occupying lesion in the } \\
\text { head of pancreas: GISTs? }\end{array}$ & Duodenum & Laparotomy & 128 & ANED \\
\hline 6 & $71 \mathrm{~F}$ & $\begin{array}{l}\text { Incidental findings during } \\
\text { examination for cystic } \\
\text { disease of kidney }\end{array}$ & $\begin{array}{l}\text { Cystic lesion in the tail of } \\
\text { pancreas }\end{array}$ & Stomach & Laparotomy & 123 & ANED \\
\hline 7 & $35 \mathrm{~F}$ & Abdominal mass & Ovarian cyst & Small intestine & $\begin{array}{l}\text { Laparotomy+ } \\
\text { Imatinib }\end{array}$ & 39 & ANED \\
\hline 8 & $73 \mathrm{~F}$ & $\begin{array}{l}\text { Incidental finding during } \\
\text { examination for appendix } \\
\text { mucinous adenocarcinoma }\end{array}$ & $\begin{array}{l}\text { Abdominal malignant } \\
\text { tumor: GISTs? }\end{array}$ & Small intestine & Laparotomy & 4 & DUD \\
\hline 9 & $31 \mathrm{~F}$ & Gastrointestinal bleeding & $\begin{array}{l}\text { Abdominal occupying } \\
\text { lesion }\end{array}$ & Stomach & Laparotomy & 75 & ANED \\
\hline 10 & $72 \mathrm{~F}$ & Abdominal mass & $\begin{array}{l}\text { Cystic lesion between liver } \\
\text { and stomach: GISTs }\end{array}$ & Stomach & Laparotomy & 79 & ANED \\
\hline 11 & $61 \mathrm{~F}$ & $\begin{array}{l}\text { Incidental finding during } \\
\text { physical examination }\end{array}$ & $\begin{array}{l}\text { Abdominal cystic lesion: } \\
\text { GISTs? }\end{array}$ & Stomach & Laparotomy & 36 & ANED \\
\hline 12 & $62 \mathrm{M}$ & Abdominal pain & $\begin{array}{l}\text { Abdominal cystic lesion: } \\
\text { GISTs? }\end{array}$ & Stomach & Laparotomy & 63 & ANED \\
\hline 13 & $58 \mathrm{M}$ & Abdominal discomfort & $\begin{array}{l}\text { Abdominal occupying } \\
\text { lesion }\end{array}$ & Stomach & Laparotomy & 51 & ANED \\
\hline 14 & $47 \mathrm{M}$ & Gastrointestinal bleeding & $\begin{array}{l}\text { Abdominal occupying } \\
\text { lesion }\end{array}$ & Duodenum & Laparotomy & 59 & AWD \\
\hline 15 & $61 \mathrm{~F}$ & NA & $\begin{array}{l}\text { Abdominal occupying } \\
\text { lesion }\end{array}$ & Stomach & Laparotomy & 36 & ANED \\
\hline 16 & $68 \mathrm{M}$ & Abdominal discomfort & $\begin{array}{l}\text { Abdominal occupying } \\
\text { lesion }\end{array}$ & Stomach & Laparotomy + imatinib & 45 & ANED \\
\hline 17 & $57 \mathrm{M}$ & Abdominal pain & Diverticulum or GISTs & Small intestine & Laparotomy & 19 & ANED \\
\hline 18 & $61 \mathrm{~F}$ & $\begin{array}{l}\text { Incidental finding during } \\
\text { physical examination }\end{array}$ & Ovarian chocolate cyst & Omentum & Laparotomy & 30 & ANED \\
\hline 19 & $45 \mathrm{M}$ & NA & $\begin{array}{l}\text { Abdominal occupying } \\
\text { lesion }\end{array}$ & Small intestine & Laparotomy & 66 & ANED \\
\hline 20 & $64 \mathrm{M}$ & $\begin{array}{l}\text { Incidental finding during } \\
\text { physical examination }\end{array}$ & Pelvic occupying lesion & Small intestine & Laparotomy + imatinib & 92 & ANED \\
\hline
\end{tabular}

$A N E D$ alive with no evidence of disease, $D U D$ died of unrelated disease, $A W D$ alive with disease

collagenous fiber with little cellular component (Fig. 2b). The nuclei were of mild to moderate atypia in $17(85 \%)$ patients and mitotic count was fewer than 5/50 HPF in $18(90 \%)$ patients. In addition, hemosiderin deposits and foamy histocytes were observed in several cases. Within the cysts, there were liquefactive necrosis, hemorrhage and myxoid changes but neoplastic cells were absent. Malignant biological parameters, such as severe nuclear atypia, mucosal infiltration and muscularis propria infiltration, were discovered in nine patients but none involved more than two parameters.

The results of immunohistochemical and mutational analysis are summarized in Table 3 . All cases demonstrated positive staining for CD117 (20/20) and negative staining for desmin (20/20) (Fig. 2c). DOG-1 was positive in $14 / 15(93.3 \%)$ cases, CD34 was positive in $16 / 19(84.2 \%)$ cases, and SMA was positive in $7 / 20(35 \%)$ cases. Staining was also performed for several other antibodies, but results 


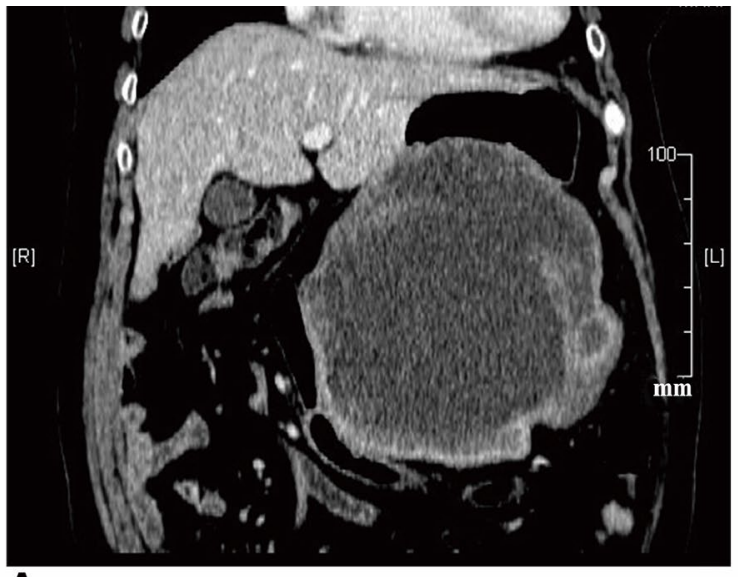

A

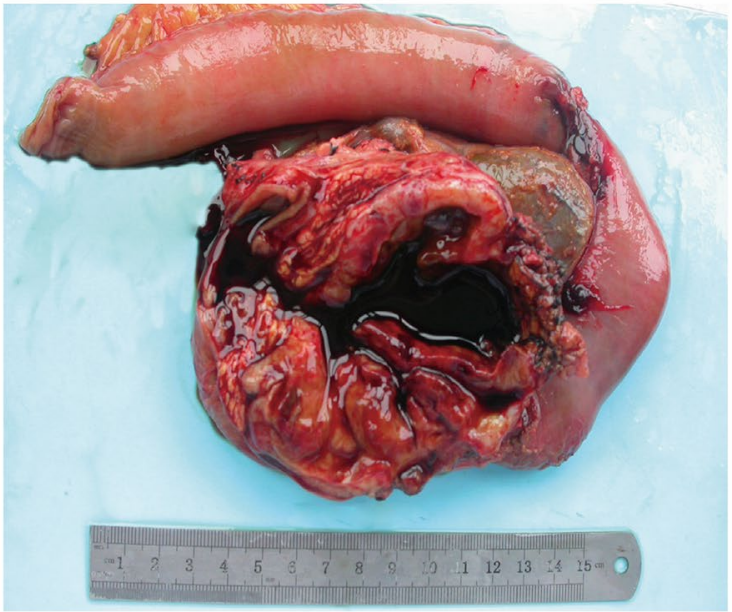

C

Fig. 1 On contrast-computed tomography (CT), cGISTs usually demonstrate an exophytic, well-defined, low-density mass with peripheral enhancement $(\mathbf{a}, \mathbf{b})$. Grossly, the cystic component made up the vast

were not included because of the limited number of cases. Mutational analyses revealed $c$-kit or PDGFR $\alpha$ mutations in eleven cases with the remaining nine being wild type for these two mutations. Among all $c$-kit/PDGFR $\alpha$ mutants, $c$-kit exon 11 point substitution was the most common (4/11), followed by $c$-kit exon 11 deletions (2/11), combination of substitution and deletions in $c$-kit exon $11(2 / 11)$, PDGFR $\alpha$ exon 18 D842V substitution (2/11) and c-kit exon 9 deletions $(1 / 11)$.

\section{Treatment and follow-up}

All patients underwent laparotomy for surgical resection of cGISTs and no severe complication occurred postoperatively. According to modified National Institute of Health (NIH) criterion, the risk of recurrence was estimated to be intermediate in 3 cases (15\%) and high in 17 cases (85\%). Based on biological behaviors proposed for evaluating

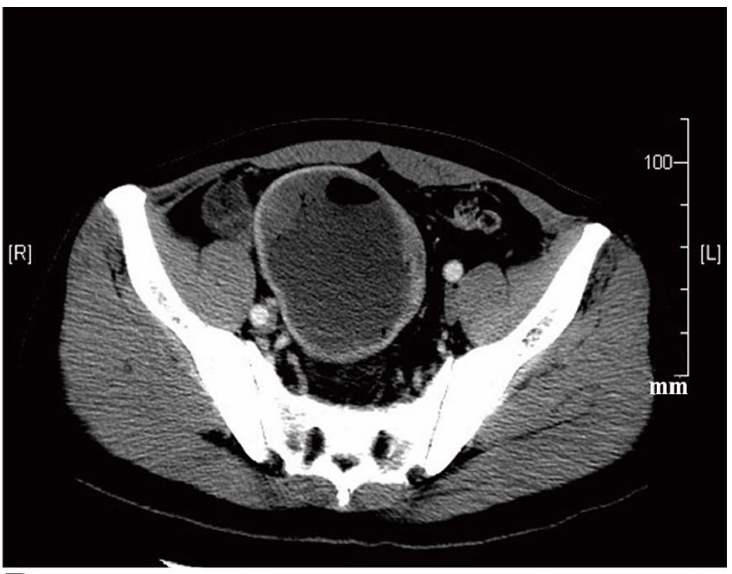

$\bar{B}$

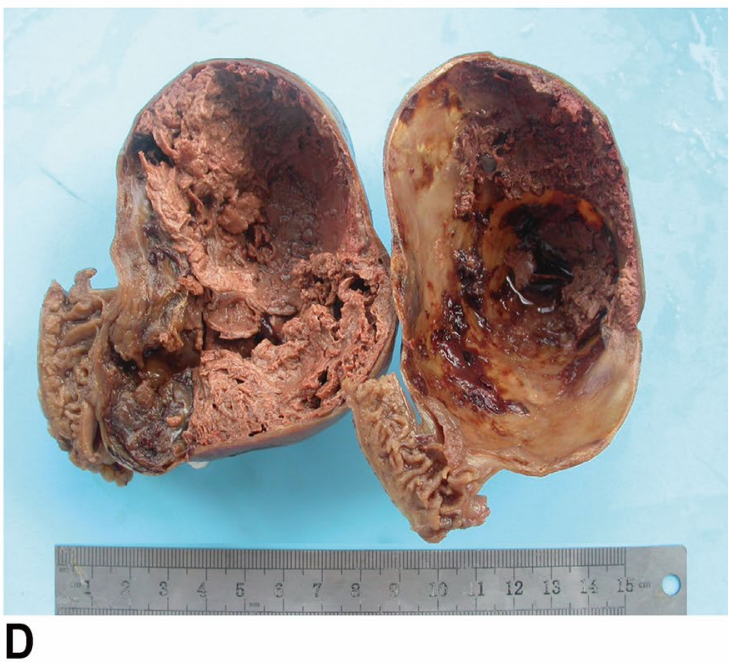

majority of the masses and was surrounded by neoplastic parenchyma variable in thickness. Most of the cysts were filled by dark bloody serous fluid and necrotic debris $(\mathbf{c}, \mathbf{d})$

GISTs by our institute, 11 patients were classified as nonmalignant and 9 as low degree of malignancy (Table 3 ). Adjuvant imatinib was carried out in 3 nonmalignant/highrisk patients (12, 30 and 39 months respectively) and no evidence of recurrence was observed during follow-up (45, 92 and 39 months respectively). For patients without adjuvant imatinib, local recurrence was detected in one (low degree of malignancy/high risk) after a median duration of 63 months (range 4-143 months). The patient underwent a second operation and postoperative imatinib therapy and was progression free after another follow-up of 35 months. One patient died of an unrelated cause 4 months after surgery, whereas all the other patients were alive till the end of follow-up (Table 1). 
Table 2 Pathologic details of 20 cases of cGIST

\begin{tabular}{|c|c|c|c|c|c|c|c|c|}
\hline Case & Size $(\mathrm{cm})$ & Focality & Cystic contents & Sectioning & Cellularity & Cellular type & $\begin{array}{l}\text { Mitosis } \\
(/ 50 \\
\text { HPF })\end{array}$ & Cellular atypia \\
\hline 1 & 15 & Unilocular & $\begin{array}{l}\text { Dark bloody necrosis } \\
\text { debris }\end{array}$ & NA & Moderate & Epithelioid & 0 & Mild-moderate \\
\hline 2 & 12 & Unilocular & Dark brown fluid & Grey/white & Moderate & Epithelioid & 3 & $\begin{array}{l}\text { Mild-moderate, partially } \\
\text { severe }\end{array}$ \\
\hline 3 & 8 & Multilocular & Light yellow clear fluid & Grey/red & Moderate & Epithelioid & 2 & Moderate-severe \\
\hline 4 & 8 & Unilocular & $\begin{array}{l}\text { Dark bloody necrotic } \\
\text { debris }\end{array}$ & Grey/white & Moderate & Spindle & 0 & Mild-moderate \\
\hline 5 & 10 & Unilocular & Dark brown fluid & Grey/white & Moderate & Spindle & 1 & $\begin{array}{l}\text { Mild-moderate, partially } \\
\text { severe }\end{array}$ \\
\hline 6 & 7 & Unilocular & Dark red fluid & Grey/red & Moderate & Spindle & 2 & Mild-moderate \\
\hline 7 & 9 & Unilocular & $\begin{array}{l}\text { Dark bloody necrotic } \\
\text { debris }\end{array}$ & Grey/brown & Moderate & Spindle & 2 & Mild-moderate \\
\hline 8 & 8 & Unilocular & Grey-green turbid fluid & Grey/red & Moderate & Spindle & 1 & Mild-moderate \\
\hline 9 & 8.5 & Unilocular & NA & NA & Moderate-Condense & Spindle & 1 & Moderate \\
\hline 10 & 16 & Unilocular & Grey-red turbid fluid & Grey/white & Moderate & Epithelioid & 0 & Moderate-severe \\
\hline 11 & 12.5 & Multilocular & NA & Grey/white & Moderate & Spindle & 1 & Mild-moderate \\
\hline 12 & 20 & Multilocular & Dark red fluid & Grey/white & Moderate & Epithelioid & 0 & $\begin{array}{l}\text { Moderate, partially } \\
\text { severe }\end{array}$ \\
\hline 13 & 13.5 & Unilocular & Brown fluid & Brown & Moderate & Spindle & 0 & Mild \\
\hline 14 & 12 & Unilocular & $\begin{array}{l}\text { Dark red necrotic } \\
\text { debris }\end{array}$ & Grey/white & Moderate & Spindle & 2 & Mild-moderate \\
\hline 15 & 13 & Unilocular & NA & NA & Moderate & Epithelioid & 11 & Moderate \\
\hline 16 & 15 & Multilocular & $\begin{array}{l}\text { Dark bloody necrotic } \\
\text { debris }\end{array}$ & Grey/white & Moderate & Spindle & 1 & Mild-moderate \\
\hline 17 & 9 & Unilocular & $\begin{array}{l}\text { Dark red necrotic } \\
\text { debris }\end{array}$ & Grey/brown & Moderate & Spindle & 0 & Moderate-severe \\
\hline 18 & 8 & Unilocular & NA & NA & Moderate & Spindle & 8 & Moderate \\
\hline 19 & 14 & Unilocular & $\begin{array}{l}\text { Dark bloody necrotic } \\
\text { debris }\end{array}$ & NA & Mild & Spindle & 1 & Moderate \\
\hline 20 & 13 & Multilocular & $\begin{array}{l}\text { Dark bloody serous } \\
\text { fluid }\end{array}$ & Grey/red & Moderate & Spindle & 0 & Mild-moderate \\
\hline
\end{tabular}

\section{Comparison between cystic and solid GISTs}

The clinicopathological characteristics of cystic GISTs in comparison with their solid counterparts are summarized in Table 4. There was no difference between the two groups in terms of age, sex, tumor location, cellular type, NIH criterion and adjuvant imatinib, except for mitotic index and numbers of biological parameters. Eighteen $(90 \%)$ cGISTs had a mitotic rate of five or fewer per 50 HPF with a median of 1/50 HPF. The number of malignant biological parameters was none in $9(45 \%)$ cGISTs and $1-2$ in $11(55 \%)$. In comparison, 85 of the $200(42.5 \%)$ solid GISTs had mitoses more than 10/50 HPF and 27 (13.5\%) had 6 to 10 mitoses per 50 HPF. Solid GISTs were more likely to manifest malignant biological behaviors, with more than 2 parameters in $81(40.5 \%)$ cases and $1-2$ parameters in $77(38.5 \%)$ cases. Of 167 solid GISTs with mutational information, $103(61.7 \%)$ harbored mutations in $c$-kit exon 11, $41(24.5 \%)$ in $c$-kit exon 9, $1(0.6 \%)$ in c-kit exon 13, 4 (2.4\%) in PDGFR $\alpha$ exon $18 \mathrm{D} 842 \mathrm{~V}$ and 18 $(10.8 \%)$ in none. In addition, survival analysis showed that patients with solid GISTs had a significantly worse recurrence-free survival (5-year $\mathrm{RFS}=66.1 \%$ ) than patients with cGISTs (5-year RFS =94.4\%) (Fig. 3).

\section{Discussion}

Gastrointestinal stromal tumors typically appear as regular, soft, solid masses, varying greatly in size and distributed within and outside the gastrointestinal tract. They are usually well circumscribed and unencapsulated with an endophytic or exophytic growth pattern. Small cystic areas are frequently observed in GISTs with large size, but GISTs rarely manifest predominantly as cystic tumors. Cases of this uncommon form have been described but no retrospective 


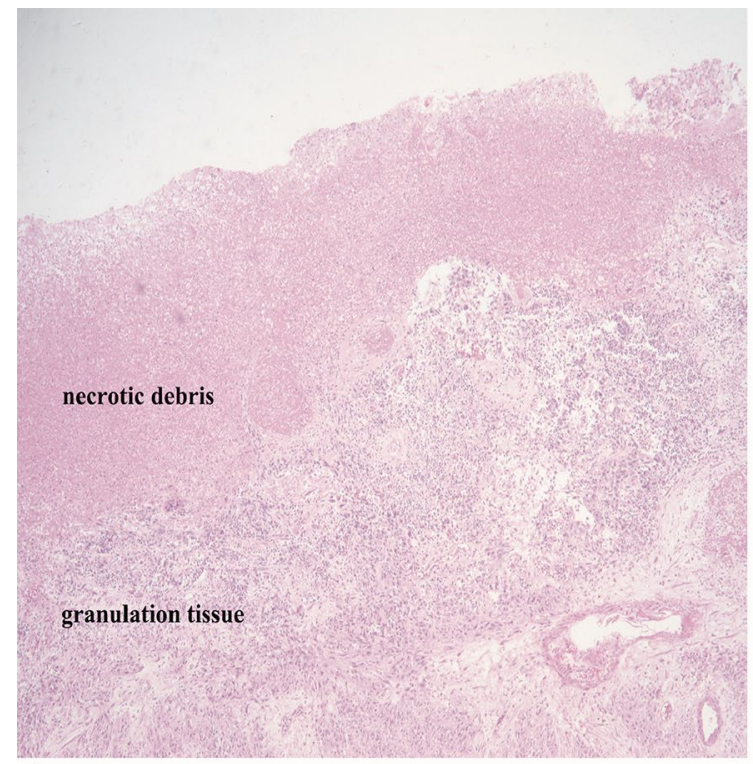

A

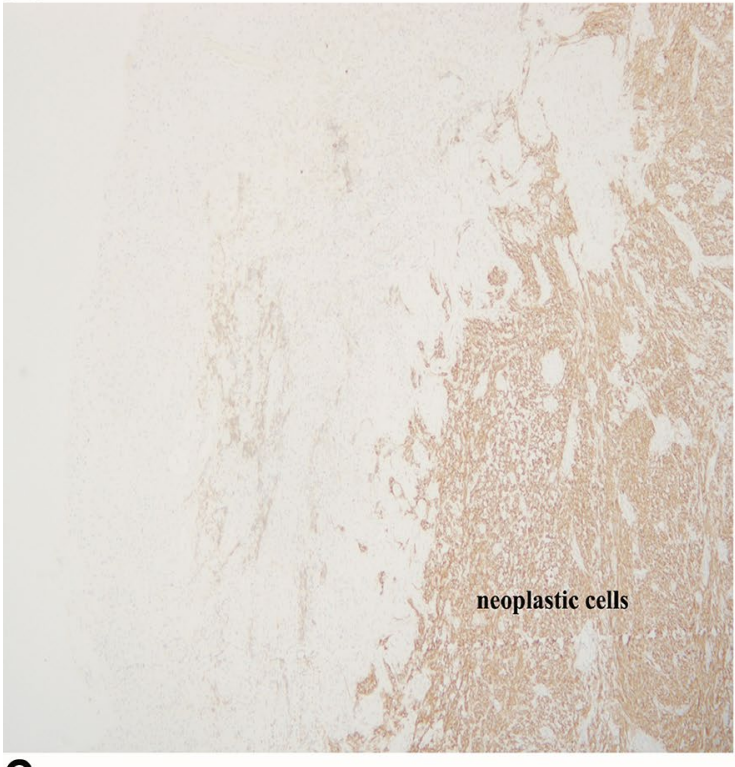

C

Fig. 2 At low magnification, cyst wall was composed of neoplastic spindle/epithelioid cells and collagenous fiber lined with necrotic debris and granulation tissue (a). In rare cases were the cyst wall occupied by collagenous fiber with little cellular component (b).

study has been reported in the English literature (Hamza et al. 2016; Okano et al. 2015; Shaikh et al. 2015; Sun et al. 2016; Takahashi et al. 2010; Wang et al. 2017; Zhu et al. 2014). In addition, clinical follow-up information was not available in most cases. In the present study, a cohort of 20 GISTs with extensive cystic change, designated as cGISTs, were evaluated to characterize their clinicopathological features and determine their biological behaviors and prognoses.

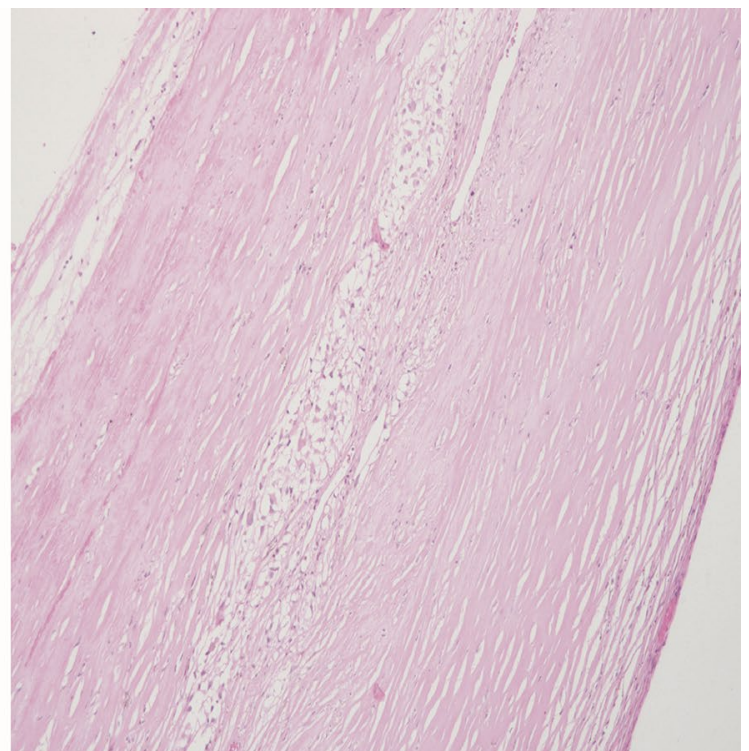

B

\section{$c$-kit exon 11 V559D}

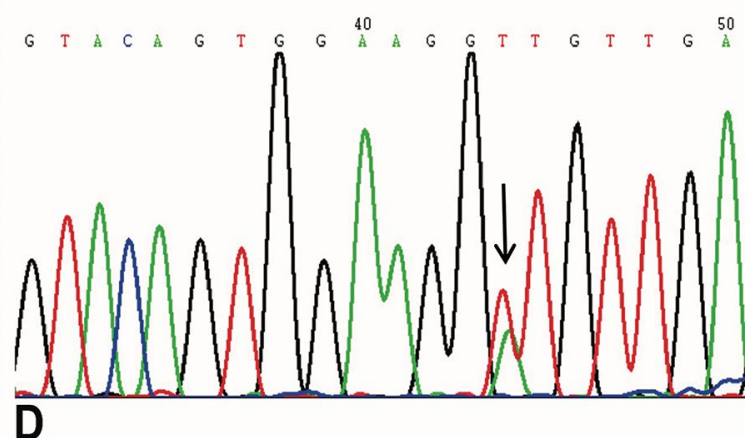

All available cases demonstrated positive staining for CD117 (c). $c$-kit exon 11 point substitution was the most common among all $c$-kit/PDGFR $\alpha$ mutants (d)

Most of the cGISTs, both in our study and prior reports, demonstrated an exophytic growth pattern and lacked pathognomonic signs or symptoms until the late stage of the disease. CT or MRI played an important role in differential diagnosis, providing evidence for original locations while excluding inconsistent neoplasms, but was not potent enough to establish exact diagnosis preoperatively. Although suggested as a useful modality for diagnosing GISTs, EUSguided FNA appears as a prudent choice for cGISTs due to the possibility of insufficient sample volume and fear of 


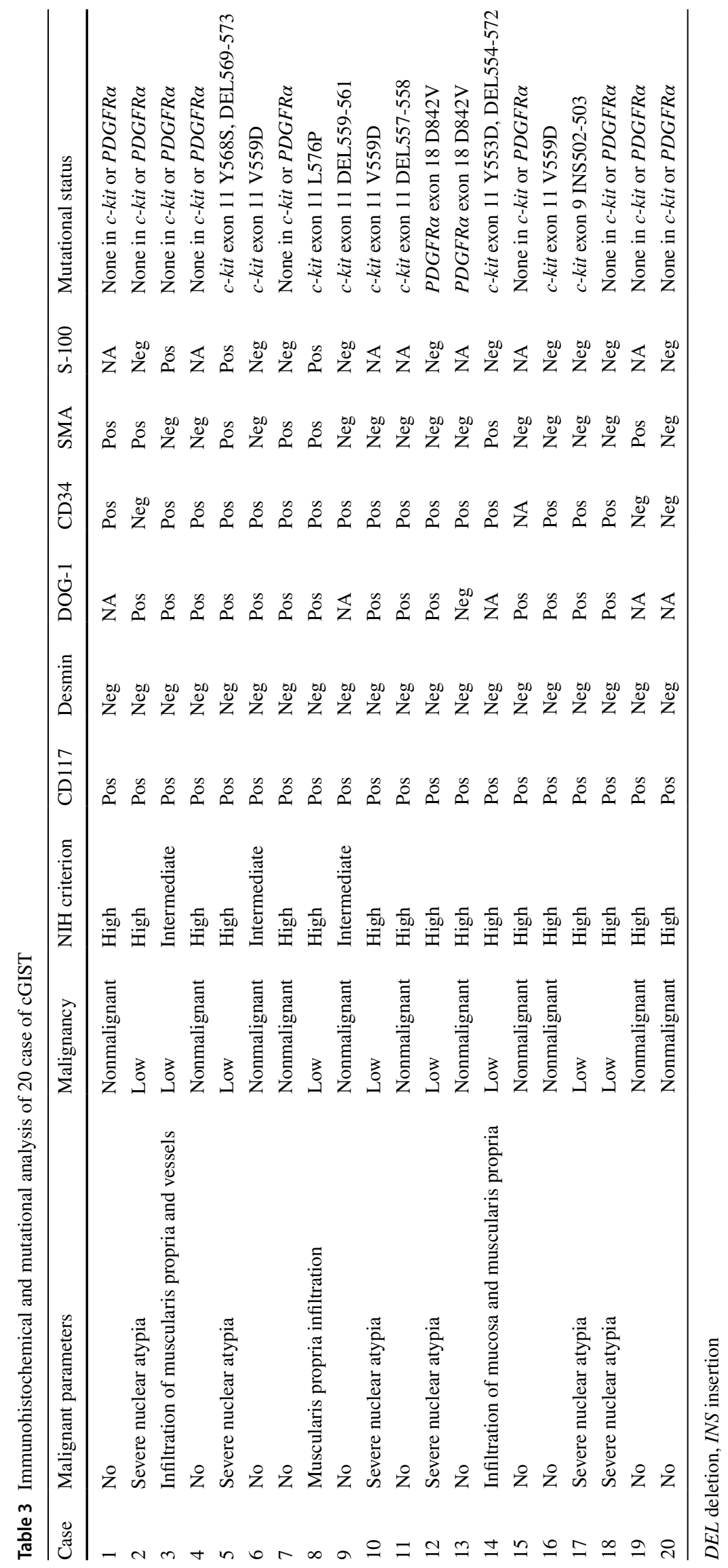


Table 4 Comparison of clinicopathological characteristics between cystic and solid GISTs

\begin{tabular}{|c|c|c|c|}
\hline & Cystic $(n=20)$ & Solid $(n=200)$ & $P$ \\
\hline Age (years) & $59.5(66-73)$ & $60(19-84)$ & 0.554 \\
\hline \multicolumn{4}{|l|}{ Sex } \\
\hline Male & 9 & 116 & \multirow[t]{2}{*}{0.263} \\
\hline Female & 11 & 84 & \\
\hline \multicolumn{4}{|l|}{ Location } \\
\hline Stomach & 10 & 117 & \multirow[t]{2}{*}{0.462} \\
\hline Non-stomach & 10 & 83 & \\
\hline \multicolumn{4}{|l|}{ Cellular type } \\
\hline Spindle & 14 & 175 & \multirow[t]{2}{*}{0.071} \\
\hline Non-spindle & 6 & 25 & \\
\hline Size $(\mathrm{cm})$ & $9(7-20)$ & $12(7-20)$ & 0.056 \\
\hline $7-9.9$ & 8 & 102 & \multirow[t]{3}{*}{0.601} \\
\hline $10-14.9$ & 8 & 70 & \\
\hline$\geq 15$ & 4 & 28 & \\
\hline Mitotic Index (/50 HPF) & $1(0-11)$ & $8(1-210)$ & $<0.001^{*}$ \\
\hline$\leq 5$ & 18 & 88 & \multirow[t]{3}{*}{$0.0004^{*}$} \\
\hline $6-10$ & 1 & 27 & \\
\hline$>10$ & 1 & 85 & \\
\hline \multicolumn{4}{|l|}{ NIH criterion } \\
\hline Intermediate & 3 & 32 & \multirow[t]{2}{*}{1} \\
\hline High & 17 & 168 & \\
\hline Predictive parameters of malignancy & $0(0-2)$ & $2(1-6)$ & $<0.001 *$ \\
\hline 0 & 11 & 42 & \multirow[t]{3}{*}{$<0.001 *$} \\
\hline $1-2$ & 9 & 77 & \\
\hline$>2$ & 0 & 81 & \\
\hline \multicolumn{4}{|l|}{ Mutational status } \\
\hline$c$-kit & 9 & 145 & \multirow[t]{3}{*}{$<0.001 *$} \\
\hline$P D G F R \alpha$ & 2 & 4 & \\
\hline Neither & 9 & 18 & \\
\hline \multicolumn{4}{|l|}{ Adjuvant imatinib } \\
\hline Yes & 3 & 49 & \multirow[t]{2}{*}{0.498} \\
\hline No & 17 & 151 & \\
\hline
\end{tabular}

$* P<0.05$ was considered statistically significant

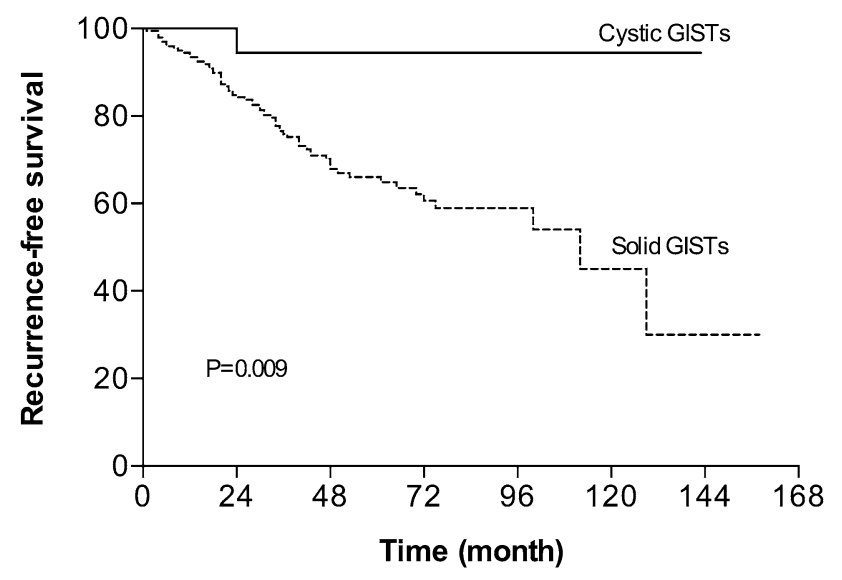

Fig. 3 Recurrence-free survival analysis (RFS) of 20 cystic and 200 solid GISTs dissemination. For all these reasons, misdiagnoses were easily made preoperatively, which included duplication cysts, mucin-producing tumors, pancreatic pseudocysts, cystic lymphangioma, cystic degeneration of other solid neoplasms, etc. Therefore, successful diagnosis of GISTs necessitates further histological and immunohistochemical examinations. Of note, diagnosis of GISTs should be considered when cystic tumors of unknown origin are encountered in the abdomen.

Pathological analysis of cGISTs revealed similar morphologic and immunohistochemical features with solid ones except that cGISTs were less likely to demonstrate malignant biological behaviors. cGISTs usually compressed or dislocated rather than invaded abutting organs. On microscopy, the mitotic figures were fewer than 5/50 HPF in the majority and malignant parameters such as mucosal invasion 
and muscularis propria infiltration were less common compared to solid GISTs of similar size (Table 3). Prominent cystic change may be responsible for their indolent behaviors, leaving only a small proportion of viable tumor cells. Cystic change of GISTs takes place in the following situations: (a) primary GISTs with expansive growth pattern, in which cystic structure takes up a large proportion, (b) cystic change induced by rapid growth rate and subsequent necrosis in malignant GISTs, (c) metastatic lesions to liver and pancreas which is cystic in nature, (d) GISTs on treatment with imatinib (Bechtold et al. 2003). Different from cystic change caused by rapid tumor growth, cGISTs are characterized by a relatively even cyst wall and fewer parameters of malignancy. As for their low frequency of $c$-kit/PDGFR $\alpha$ mutations, lack of enough neoplastic cells may be an explanation, or it is a unique inherent feature associated with their development.

To date, little is known about the cause of predominant cystic change in GISTs and we speculate that exophytic growth pattern with a small area of attachment may restrict blood supply to the tumor. Aggravated by occasional vascular obstruction and incapability of angiogenesis, congestion, hemorrhage, degeneration and liquefactive necrosis occur, resulting in remarkable cystic change. Alternatively, cystic development may be attributed to communication between tumor mass and gastrointestinal tract in certain cases. In three previously reported cases as well as one included in the present study, it is likely that ulceration of gastrointestinal mucosa allows entrance of enteric leakage into tumor mass and induces abscess formation subsequently.

Patients with cGISTs reported in the literature usually underwent surgical resection as the primary treatment but follow-up information was available in fewer than half. In our series, surgery was also the therapy of choice, with three patients receiving additional adjuvant imatinib. Recurrence was detected in one patient without adjuvant imatinib (low degree of malignancy/high risk) and brought under control by surgery and imatinb. In comparison, the 5-year RFS was $66.1 \%$ in patients with solid GISTs of similar size. We can say from our experience that surgery is safe and effective for patients with cGISTs. In view of lack of pathology and risk of rupture, preoperative administration of imatinib is not warranted. According to modified NIH criterion, the majority of cGISTs ( $85 \%$ in our series) was stratified as high risk of recurrence and necessitates adjuvant imatinib. However, to avoid excessive administration of imatinib, we recommend meticulous evaluation of malignant parameters prior to decision. For patients with cGISTs classified as nonmalignant, surgical resection alone may achieve long-term recurrence free survival; for patients with cGISTs classified as low degree of malignancy, adjuvant imatinib should be considered but its benefit might be counteracted by low incidence of recurrence.
Several limitations were implicit in our study. First, the cases included were from surgical pathology database and consultation files over a long period of time, resulting in incomplete clinical and pathological information. Second, it was a retrospective study with a limited sample size, which renders the conclusions provisional and warrants further investigations. Third, the magnitude of cystic change was assessed according to radiology reports and/or gross reports. A more qualitative determination of tumor cells may need to perform during radiologic and pathological examinations.

In conclusion, although similar to solid GISTs in terms of morphologic and immunohistochemical features, cGISTs should be considered as a specific subtype of GISTs with relatively indolent behaviors and favorable prognoses. Parameters of malignancy are more applicable than modified NIH criterion in determining recurrence risk and whether to administrate adjuvant imatinib. Future studies analyzing a larger cohort with more detailed information should help shed light on the pathogenesis and long-term survival for these neoplasms.

Acknowledgements This study was supported by Shanghai Municipal Commission of Health and Family Planning, key developing discipline (NO. 2015ZB0201) and Shanghai Municipal Science and Technology Commission (14411970000).

\section{Compliance with ethical standards}

Conflict of interest All the authors listed have approved the manuscript and no conflict of interest exists

Ethical approval Study approval was obtained from the institutional review board at Zhongshan Hospital, Fudan University.

OpenAccess This article is distributed under the terms of the Creative Commons Attribution 4.0 International License (http://creativeco mmons.org/licenses/by/4.0/), which permits unrestricted use, distribution, and reproduction in any medium, provided you give appropriate credit to the original author(s) and the source, provide a link to the Creative Commons license, and indicate if changes were made.

\section{References}

Bechtold RE, Chen MY, Stanton CA, Savage PD, Levine EA (2003) Cystic changes in hepatic and peritoneal metastases from gastrointestinal stromal tumors treated with. Gleevec Abdom Imaging 28:808-814

Corless CL (2014) Gastrointestinal stromal tumors: what do we know now? Mod Pathol Off J US Can Acad Pathol 27(Suppl 1):S1-S16 https://doi.org/10.1038/modpathol.2013.173

Fletcher CD et al (2002) Diagnosis of gastrointestinal stromal tumors: a consensus approach. Hum Pathol 33:459-465

Hamza AM, Ayyash EH, Alzafiri R, Francis I, Asfar S (2016) Gastrointestinal stromal tumour masquerading as a cyst in the lesser sac. BMJ Case Rep. https://doi.org/10.1136/bcr-2016-215479 
Heinrich MC et al (2003) PDGFRA activating mutations in gastrointestinal stromal tumors. Science (New York NY) 299:708-710. https://doi.org/10.1126/science.1079666

Hou YY, Lu SH, Zhou Y, Qi WD, Shi Y, Tan YS, Zhu XZ (2009a) Stage and histological grade of gastrointestinal stromal tumors based on a new approach are strongly associated with clinical behaviors. Mod Pathol Off J US Can Acad Pathol 22:556-569. https://doi.org/10.1038/modpathol.2009.11

Hou YY et al (2009b) Predictive values of clinical and pathological parameters for malignancy of gastrointestinal stromal tumors. Histol Histopathol 24:737-747. https://doi.org/10.14670/hh-24.737

Kindblom LG, Remotti HE, Aldenborg F, Meis-Kindblom JM (1998) Gastrointestinal pacemaker cell tumor (GIPACT): gastrointestinal stromal tumors show phenotypic characteristics of the interstitial cells of Cajal. Am J Pathol 152:1259-1269

Miettinen M, Lasota J (2006) Gastrointestinal stromal tumors: pathology and prognosis at different sites. Semin Diagn Pathol 23:70-83

Okano H et al (2015) A case of a stomach gastrointestinal stromal tumor with extremely predominant cystic formation. Clin J Gastroenterol 8:197-201. https://doi.org/10.1007/s12328-015-0577-8

Shaikh ST, Upwanshi MH, Shetty TS, Ghetla SR, Gheewala H (2015) A large cystic variant of gastro-intestinal stromal tumour arising from the Jejunum: a case report. J Clin Diagn Res JCDR 9:Pd11Pd12. https://doi.org/10.7860/jcdr/2015/12074.5813

Sun KK, Xu S, Chen J, Liu G, Shen X, Wu X (2016) Atypical presentation of a gastric stromal tumor masquerading as a giant intraabdominal cyst: a case report. Oncol Lett 12:3018-3020. https://doi.org/10.3892/ol.2016.4968

Takahashi R, Nagayama S, Mori Y, Isoda H, Yoshizawa A, Manabe T, Sakai Y (2010) A large cystic gastrointestinal stromal tumor of the rectum in the retrorectal space. Int J Clin Oncol 15:601-607. https://doi.org/10.1007/s10147-010-0084-3

von Mehren $M$ et al (2018) Soft tissue sarcoma, Version 2.2018, NCCN clinical practice guidelines in oncology. J Natl Compr Cancer Netw JNCCN 16:536-563. https://doi.org/10.6004/jncen .2018 .0025

Wang L, Liu L, Liu Z, Tian Y, Lin Z (2017) Giant gastrointestinal stromal tumor with predominantly cystic changes: a case report and literature review. World J Surg Oncol 15:220. https://doi. org/10.1186/s12957-017-1285-2

Zhu CC, Liu Y, Zhao G (2014) Exophytic gastrointestinal stromal tumor with cystic changes: a case report. Oncol Lett 7:1427-1429. https://doi.org/10.3892/ol.2014.1954

Publisher's Note Springer Nature remains neutral with regard to jurisdictional claims in published maps and institutional affiliations. 